\title{
9. SIMULATION OF BOREHOLE FLUID MIXING ON THE BASIS OF GEOCHEMICAL OBSERVATIONS, HOLE 504B ${ }^{1}$
}

\author{
Andrew J. Magenheim ${ }^{2,3}$ and Joris M. Gieskes ${ }^{2}$
}

\begin{abstract}
Borehole fluid samples have been collected from Hole 504B before drilling on a total of seven expeditions. The chemical compositions have revealed that these fluids can be described as a mixture of unaltered seawater with a single reacted fluid component. In addition, analyses of tritium provide unequivocal evidence that some of the surface seawater, originally placed in the borehole during circulation on the leg before sampling, remains after periods of up to 1233 days. In this manuscript we take a numerical approach to simulate the vertical mixing of the borehole fluids to account for the displacement of surface seawater by mixing with bottom seawater. The simulations demonstrate that the composition of borehole fluids from Hole 504B can result from vertical mixing of seawater with a reacted fluid component present in the rubble at the hole bottom. This implies that formation water is not present in the borehole waters as previously suggested. We show that the mixing required to produce the geochemical observations would not disrupt the temperature profile. Finally, we demonstrate observed geochemical trends would not be observed if borehole mixing is the process responsible for the observed $40 \%$ reduction in the temperature gradient below $850 \mathrm{mbsf}$ in Hole 504B.
\end{abstract}

\section{INTRODUCTION}

Borehole fluids were collected from Hole 504B on a total of seven expeditions. Fluids discussed in this paper were collected in the "passive mode" (Mottl and Gieskes, 1990), in which water was collected from the open borehole rather than being drawn under negative pressure from the interstices of the wall rocks. After the borehole was undisturbed during the interim between drilling legs, sampling was conducted during initial logging operations on a given leg before any drilling disturbance. The original intent of this sampling program was to collect formation fluids that may have exchanged with the surface seawater originally placed in the borehole. The fluids collected during each expedition have compositions significantly different from seawater, and are consistent with seawater/basalt reaction at temperatures ranging from $80^{\circ}$ to $160^{\circ} \mathrm{C}$. However, the origin of these reacted fluids has remained equivocal.

Sampling borehole fluids is technically difficult, and many failures related to equipment malfunction, sample integrity, and artifacts created by the sampling process, have been encountered and are discussed elsewhere (e.g., Shipboard Scientific Party, 1993). The preparation of the borehole for water sampling during subsequent legs involves the circulation of surface seawater for an extended period to remove drilling mud and debris. This is critical for a meaningful interpretation of borehole fluid samples collected during the subsequent leg. In addition to cleaning the borehole this process fills the borehole with surface seawater, which can be compositionally distinguished from both deep seawater and formation fluids. Inefficient circulation, resulting in significant quantities of drilling mud left in the borehole, adversely affected borehole samples collected during Legs 92 and 148 (Gieskes et al., 1986; Shipboard Scientific Party, 1993).

Mottl and Gieskes (1990) provide a description of the borehole fluid samples from Legs 69, 70, 83, 92 and 111. Fluid samples from

Alt, J.C., Kinoshita, H., Stokking, L.B., and Michael, P.J. (Eds.), 1996. Proc, ODP. Sci. Results, 148: College Station. TX (Ocean Drilling Program).

2University of California San Diego, Scripps Institution of Oceanography, Marine Research Division Mail Code 0215, La Jolla, CA 92093-0215, U.S.A. Gieskes: JGieskes@ucsd.edu

'Present address: Department of Geological Sciences, San Diego State University, San Diego, CA 92182-2020,U.S.A. amagenhe@mail.sdsu.edu
Leg 137 are discussed in Magenheim et al. (1995), and the samples from Leg 148 are discussed by the Shipboard Scientific Party (1993). The borehole fluids have compositions close to that of unaltered bottom seawater to a depth of at least $400 \mathrm{mbsf}$ (Mottl and Gieskes, 1990; Magenheim et al., 1995). This is considered a consequence of downward flow of bottom seawater through the casing into the upper $100 \mathrm{~m}$ of the formation as a result of hydrostatic underpressure (Becker et al., 1983). Below 400 mbsf, decreases in salinity, $\mathrm{Mg}, \mathrm{Na}$, $\mathrm{K}$, and $\mathrm{SO}_{4}{ }^{2-}$ and increases in $\mathrm{Ca}$ and $\mathrm{Si}$ are observed in the sampled borehole fluids (e.g., Figs. 1A, B). Compositional changes from seawater increase with depth in the borehole for samples from all legs. In addition to the general downhole trends observed, the borehole fluids can be described as compositional mixtures between unaltered seawater and a reacted fluid component (e.g., Fig. 1C). Magenheim et al. $(1992 ; 1995)$ demonstrate that the reacted fluid end-member (taken at $\mathrm{Mg}=0$ ) is unique for each expedition, with compositional changes from seawater increasing as the borehole has been drilled deeper into the hotter formation. Interpretation of these results, combined with the observation of alteration skins on pieces of rubble collected from the borehole before drilling during Leg 137, led to the hypothesis that the source of the reacted fluid component found in the borehole samples was seawater/basalt reaction within the rubble at the hole bottom (Magenheim et al., 1995).

Four processes may potentially alter the composition of the borehole fluids (modified from Mottl and Gieskes, 1990):

1. advection of formation fluids into the borehole through fracture(s),

2. molecular diffusive exchange between the borehole fluids and formation fluids through the borehole walls,

3. vertical displacement of the borehole fluid by convection, and

4. in situ reaction of the borehole fluids with the borehole wall rocks.

The first three processes involve the displacement of the surface seawater originally placed in the borehole, although reaction with the wall rock will merely change its composition. Mottl et al. (1985) proposed the use of tritium as a tracer of the surface seawater component in the borehole fluids. Tritium is a definitive tracer for surface seawater as it is abundant in surface water of the oceans because of atmospheric nuclear testing in the 1950s and 1960s. It is 
A
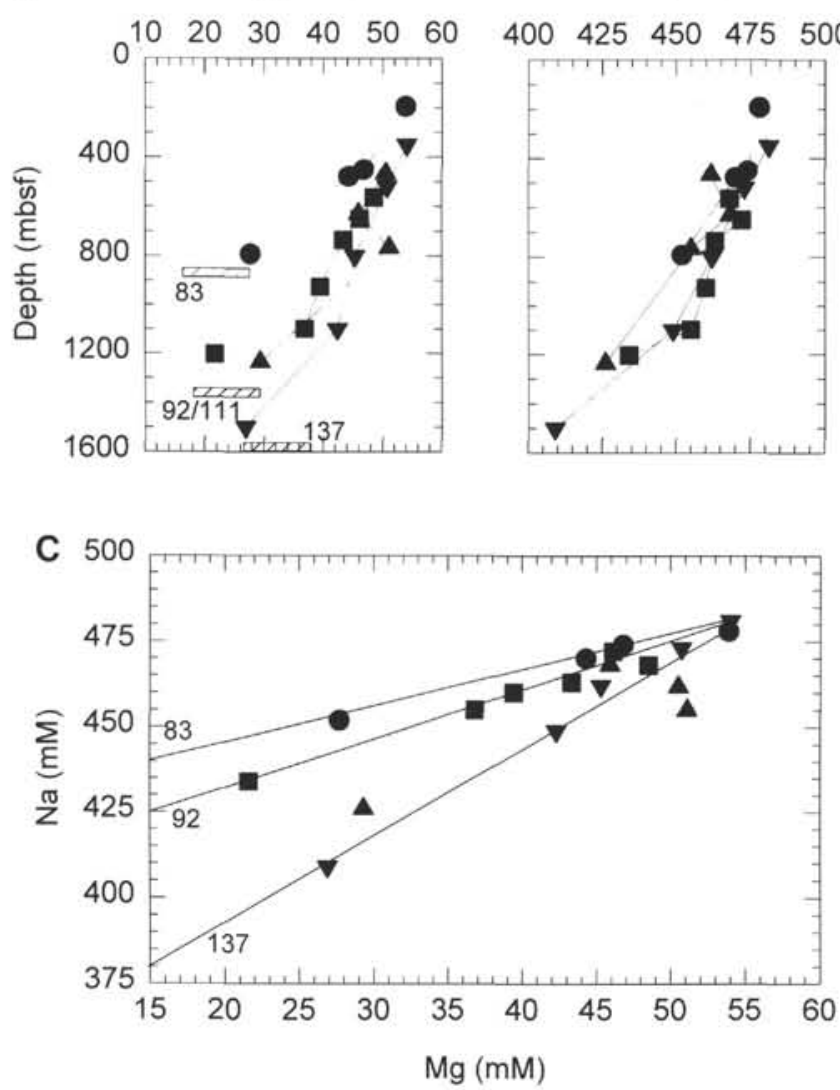

Figure 1. Example chemical trends in Hole 504B borehole fluids from Legs $83,92,111$, and 137. A. Mg concentration profiles. B. Na concentration profiles. C. Mg vs. Na mixing diagram. Data for Legs 83-111 are from Mottl and Gieskes (1990, and references therein), and are not corrected for $\mathrm{NO}_{3}^{-}$ (see Magenheim et al., 1995). Data from Leg 137 are from Magenheim et al. (1995). . Circles $=\operatorname{Leg} 83$, squares $=\operatorname{Leg} 92$, triangles $=\operatorname{Leg} 111$, and inverted triangles $=$ Leg 137. Hatched area shows the borehole depth for each leg. Samples that were obviously diluted with seawater during sampling have been omitted.

generally absent from deep-ocean water masses in the Pacific (and therefore formation waters as well) as a result of its short half life $(12.3 \mathrm{yr})$ and relatively recent introduction into the environment. Thus, the concentration of tritium in the borehole fluids is a conservative tracer for the surface seawater originally emplaced during the flushing of the borehole at the end of the leg preceding the sampling. If surface water (whether reacted or not) remains in the borehole, then the quantity that remains may limit the extent to which processes 1 through 3 (above) have operated during the interim. Because the time between drilling legs varied (ranging from 470 to 1500 days), differences in the observed amount of surface seawater remaining in the borehole can be related directly to the rates at which these displacement processes occur.

Mottl and Gieskes (1990) used the available tritium data (from Legs 83,92, and 111) to assess the importance of molecular diffusive exchange with formation fluids over the time intervals appropriate for each borehole sampling expedition. They used a finite difference approach for radial diffusion through the borehole walls. Their analysis suggested that significant exchange by radial molecular diffusion could account for displacement of up to $70 \%$ of the surface seawater during the 1233-day interim between Legs 92 and 111 (Table 1). However, in almost all cases the measured tritium was less than the calculated value, indicating that an additional exchange pro-
Table 1. Predicted vs. measured tritium concentrations corrected from Mottl and Gieskes (1990).

\begin{tabular}{|c|c|c|c|c|c|c|c|}
\hline Leg & $\begin{array}{l}\text { Depth } \\
\text { (mbsf) }\end{array}$ & $\begin{array}{c}\text { Temperature } \\
\left({ }^{\circ} \mathrm{C}\right)\end{array}$ & $\begin{array}{c}\text { Apparent } \\
\text { porosity } \\
(\%)\end{array}$ & $\begin{array}{c}\text { Predicted } \\
\text { tritium } \\
\text { (T.U.) }\end{array}$ & $\begin{array}{c}\text { Modified } \\
\text { predicted } \\
\text { tritium } \\
\text { (T.U.) }\end{array}$ & $\begin{array}{l}\text { Measured } \\
\text { tritium } \\
\text { (T.U.) }\end{array}$ & $\mathrm{F}_{\mathrm{ssw}}$ \\
\hline 83 & Surface $\mathrm{H}_{2} \mathrm{O}$ & & & & & 2.687 & \\
\hline 83 & 479 & 81 & 8.6 & 1.40 & 2.57 & 0 & 0 \\
\hline 83 & 793 & 116 & 9.6 & 1.11 & 2.53 & 0.83 & 0.31 \\
\hline 92 & Surface $\mathrm{H}_{2} \mathrm{O}$ & & & & & 2.501 & \\
\hline 92 & 926 & 128 & 4.0 & 1.86 & 2.3 & 0.32 & 0.13 \\
\hline 92 & 1099 & 138 & 2.4 & 2.11 & 2.39 & 0.60 & 0.24 \\
\hline 111 & Surface $\mathrm{H}_{2} \mathrm{O}$ & & & & & 2.072 & \\
\hline iii & 466 & 81 & 8.9 & 0.85 & 1.93 & 0.08 & 0.04 \\
\hline III & 766 & 115 & 9.6 & 0.63 & 1.90 & 0.13 & 0.07 \\
\hline iii & 1236 & 146 & 1.4 & 1.76 & 1.87 & 0.53 & 0.26 \\
\hline
\end{tabular}

Notes: Surface-seawater tritium concentrations for Legs 92 and 111 are calculated on the basis of radioactive decay from the Leg 83 value, and may introduce considerable error in the calculation of $\mathrm{F}_{\mathrm{ssw}}={ }^{3} \mathrm{H}_{\text {measured }}{ }^{3} \mathrm{H}_{\mathrm{ssw}}$. The corrected predicted values are calculated using the model presented in Mottl and Gieskes (1990) with the revised porosity of $1 \%$ on the basis of estimates of Pezard (1990). $\mathrm{F}_{\mathrm{ssw}}$ is the fraction of surface seawater remaining in the borehole calculated by dividing the measured tritium concentration by that in the surface seawater. Tritium concentrations for the surface water for Legs 92 and 111 are calculated values on the basis of radioactive decay from the surface water ${ }^{3} \mathrm{H}$ concentration from Leg 83 . T.U. = tritium units.

cess or processes must have been important. It is important to note that the calculations provided by Mottl and Gieskes (1990) are dependent on the formation porosity, which the authors took from the estimates of Becker et al. (1982) based on electrical resistivity logs. The estimated formation porosities have since been revised downward to values near $1 \%$ below the upper $100 \mathrm{~m}$ of basement based on an evaluation of the contribution of electrical conduction of clays (present in the alteration products within the formation) to the measured electrical resistivity (Pezard, 1990). Recalculation of the predicted tritium concentrations, based on the revised porosities of $\sim 1 \%$, indicates that in the most extreme case only $10 \%$ of the surface seawater can be displaced by molecular diffusion (Table 1). In view of the corrected porosities, we conclude that exchange by molecular diffusion is of minimal importance for the transport of formation fluids into the borehole.

Thus, given the large displacement of surface water from the borehole, the dominant processes must include either vertical convective exchange of the fluids, and/or displacement by advective flow of formation fluids into the borehole. Intuitively, if the reacted fluid component is supplied through a fracture located somewhere in the borehole, we would expect to see a single reacted fluid component (or mixing trend) for all legs regardless of total borehole depth and maximum temperature. Also, the maximum deviation from seawater composition should occur in the vicinity of the aquifer. Because the deepest samples from all legs show the largest deviation from seawater, and the composition of the reacted fluid end-member changed as the hole was deepened (Magenheim et al., 1992), advection of formation water into the borehole seems unlikely. Therefore, vertical displacement by bottom seawater must be the dominant process that removes surface water from the borehole.

An analysis of the temperature profile in the borehole has been conducted that suggests that the borehole fluid should be supercritical for free (buoyancy-driven) convection (Fisher and Becker, 1991). The calculated Rayleigh number for the thermal conditions present in the borehole exceeds the Rayleigh number for the lowest critical mode of convection (antisymmetric convection, where fluid rises up one side of the borehole and descends down the other) by a factor of greater than $10^{4}$ (Fisher and Becker, 1991). However, quantitative description of convection occurring in Hole 504B is difficult, because of the complex geometry of the borehole walls. Given the large instability of the fluid toward buoyancy-driven convection, it is difficult to account for why convection has not eliminated thermal and geochemical gradients in the borehole. Fisher and Becker (1991) sug- 
gest that turbulent convection is broken into small cells ( $1-2 \mathrm{~m})$ and is unstable, which explains the inefficiency to homogenize the borehole fluids thermally and geochemically.

A time-dependent box model is presented to describe mixing within Hole 504B. This model is used to describe the displacement of surface water by bottom seawater, and adequately simulates the tritium results from Legs 83, 92, and 111. The downhole $\mathrm{Mg}$ profiles are simulated by specifying a reactive flux between the bottom-most box and the fluids from within the rubble accumulated at the borehole bottom. The results indicate that vertical convective mixing and reaction within the rubble can explain the vertical geochemical gradients in Hole 504B. In addition, the effect of mixing on the thermal structure of the borehole is considered. Finally, we analyze the degree of mixing necessary to produce the reduction in the temperature gradient observed in Hole 504B below 850 mbsf.

\section{MODEL FORMULATION}

The approach we chose to model the mixing in Hole 504B is essentially a vertically oriented box model with exchange between adjacent boxes (Fig. 2). We assume that the boxes are well mixed internally and that mixing can be described by linear exchange dependent on the concentration of a substance in each box. The flux for transfer from box $i$ to box $i+l$ is specified as

$$
\left.\frac{d X_{i}}{d t}\right|_{i, i+1}=\beta_{i, i+1} V_{i} C_{i},
$$

where the subscripts refer to the specific boxes involved in the process, $X_{i}$ is the quantity of a substance, $V_{i}$ is the volume of box $i, C_{i}$ is the concentration of $X$, and $\beta_{i, i+1}$ is the volume transferred from box $i$ to box $i+l$ divided by $V_{i}$ per unit time $\left(\mathrm{s}^{-1}\right)$. The value of $\beta_{i, i+1}$ can be regarded as the exchange efficiency, the fractional volume of box $i$ transferred to box $i+l$ per unit time $\left(V_{i}^{-t} d V / d t\right)$. Because each box is affected by exchange with boxes immediately adjacent to it (Fig. 2) in this borehole mixing model, the net flux into an individual box can be described as

$$
\begin{gathered}
\frac{d X_{i}}{d t}=\beta_{i-1, i} V_{i-1} C_{i-1}-\beta_{i, i-1} V_{i} C_{i} \\
-\beta_{i, i+1} V_{i} C_{i}+\beta_{i+1, i} V_{i+1} C_{i+1} .
\end{gathered}
$$

Because $\beta_{i, j}$ should be related to the temperature gradient within the box, and the temperature appears to be at steady state within the borehole (Gable et al., 1989), we assume that the exchange efficiencies from box $i$ to box $i-l\left(\beta_{i, i-1}\right)$ and to box $i+l\left(\beta_{i, i+1}\right)$ are equal, hence:

$$
\beta_{i, i-1}=\beta_{i, i+1}=\beta_{i},
$$

and from mass/volume balance:

$$
\beta_{i, i+1} V_{i}=\beta_{i+1, i} V_{i+1} \text { or } \beta_{i+1}=\beta_{i} \frac{V_{i}}{i+1} .
$$

Substituting Equations $3 \mathrm{a}$ and $3 \mathrm{~b}$ into Equation 2 and solving for the change in concentration with time:

$$
\frac{d C_{i}}{d t}=\frac{d X_{i}}{d t} / V_{i}=\beta_{i} C_{i-1}-2 \beta_{i} C_{i}+\beta_{i} C_{i+1} .
$$

Equation 4 describes the change in concentration resulting from mixing between adjacent boxes within the borehole. However, for the boxes at the boundaries, boxes $i=l$ and $i=n$, slight modifications are necessary (Fig. 2):

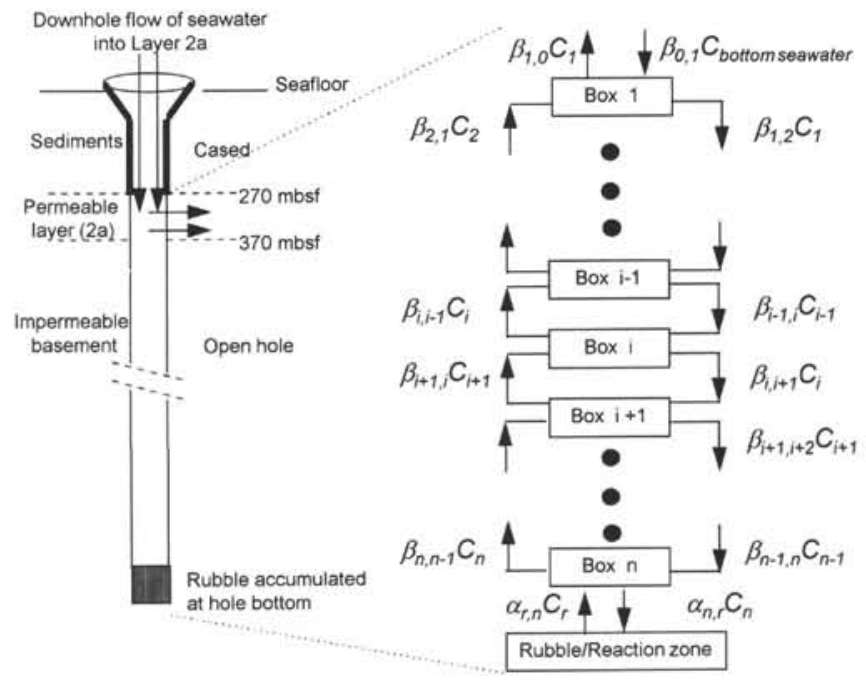

Figure 2. Schematic representation of the box model used for simulation of borehole mixing (see text). On the left a representation of the borehole is given, including the flow of bottom seawater into the upper basement, permeable Layer $2 \mathrm{a}$. On the right a box model diagram describes the mixing between boxes in the borehole. $\beta_{i, j}$ are the values of the exchange coefficient resulting from mixing in the borehole; $\alpha_{n, r}$ are the values of the coefficient for exchange between the $n^{\text {th }}$ box and the fluids within the rubble pile (believed to be the reacted fluid component, see text). Hatched area shows the borehole depth for each leg.

$$
\frac{d C_{I}}{d t}=\beta_{I} C_{0}-2 \beta_{l} C_{1}+\beta_{l} C_{2},
$$

where $C_{0}$ is constant, set at the concentration of substance $X$ in the bottom water supplied by rapid flow into the upper part of the basement above box $i=l$. For lower boundary, box $i=\mathrm{n}$ :

$$
\frac{d C_{n}}{d t}=\beta_{n} C_{n-1}-\beta_{n} C_{n},
$$

as box $\mathrm{n}$ can only have exchange with box $\mathrm{n}-1$ (ignoring potential exchange with fluid in the rubble at this time). Note that Equation 4 is essentially identical to the finite difference approximation for a diffusive flux:

$$
\frac{d C_{i}}{d t}=-\kappa \frac{d^{2} C}{d z^{2}}=\kappa \frac{\left(C_{i-1}-2 C_{i}+C_{i+1}\right)}{h^{2}},
$$

where $\kappa$ is the diffusivity $\left(\mathrm{m}^{2} / \mathrm{s}\right)$, and $h$ is the height of the box. Thus, $\beta=\kappa / h^{2}$, and, therefore, the value of the diffusivity appropriate for mixing should be independent of the box height or the number of boxes. The equations describing the change in concentration with time $(4-4 b)$ can be expressed in matrix notation for the entire borehole $(i=I$ to $n)$ as

$$
\mathbf{C}^{\prime}=\mathbf{A C}+\mathbf{b},
$$

where $\mathbf{C}^{\prime}$ and $\mathbf{C}$ are $\mathrm{n} \times 1$ vector matrices containing values of $d C_{i} / d t$ and $C_{i}$, respectively, and $\mathbf{A}$ is the $\mathrm{n} \times \mathrm{n}$ matrix containing the constant coefficients:

$$
\mathbf{A}=\left[\begin{array}{ccccc}
-2 \beta_{l} & \beta_{1} & 0 & 0 & \ldots \\
\beta_{2} & -2 \beta_{2} & \beta_{2} & 0 & \ldots \\
0 & \beta_{3} & -2 \beta_{3} & \beta_{3} & \ldots \\
\ldots & \ldots & \ldots & \ldots & \ldots \\
\ldots & \ldots & \ldots & \beta_{n} & -\beta_{n}
\end{array}\right],
$$


and $\mathbf{b}$ is the $\mathrm{n} \times 1$ matrix containing fluxes that are independent of the changes in concentrations in the borehole, in this case,

$$
\mathbf{b}=\left[\begin{array}{c}
\beta, C_{0} \\
0 \\
0 \\
\cdots \\
0
\end{array}\right] .
$$

Equation 6 can be solved for $\mathbf{C}(\mathbf{t})$ at time $t$ after Lasaga (1980):

$$
\mathbf{C}(\mathrm{t})=\underline{\mathrm{V}}\left(\mathbf{I} e^{\Lambda t}\right) \underline{\mathrm{V}}^{-1}\left[\mathrm{C}(\mathbf{0})+\mathrm{A}^{-1} \mathbf{b}\right]-\mathrm{A}^{-1} \mathbf{b},
$$

where $\Lambda$ is the $n \times 1$ matrix containing the eigenvalues of $\mathbf{A}, \underline{\mathbf{V}}$ is the $\mathrm{n} \times \mathrm{n}$ matrix of eigenvectors of $\mathbf{A}, \mathbf{I}$ is the $\mathrm{n} \times \mathrm{n}$ identity matrix, and $\mathbf{C}(\mathbf{0})$ is the $\mathrm{n} \times 1$ matrix containing the concentrations at time zero.

We present results for mixing in the borehole with uniform box heights of $30 \mathrm{~m}$ for all legs so we can compare results from different legs directly (assuming that $\kappa_{i}$ remains constant for different legs). The depth of $370 \mathrm{mbsf}$ is taken as the upper boundary, as this is the depth at which the permeability and presumably formation underpressure are no longer large enough to draw fluid into the formation (cf., Becker et al., 1983; Fisher and Becker, 1991). The composition at $370 \mathrm{mbsf}$ is, therefore, equal to that of bottom seawater (Fig. 2). Table 2 contains the pertinent information including time between drilling legs, total depth, and number of boxes used in the simulations of the profiles for individual drilling legs.

\section{CALCULATIONS AND RESULTS}

\section{Simulation of Surface Water Removal by Vertical Mixing}

The fraction of surface seawater $\left(\mathrm{F}_{\mathrm{ssw}}\right)$ remaining in the borehole after a time equal to the time between legs can be calculated from Equation 6 to compare the results obtained by tritium measurements (Table 1). The initial condition $\mathrm{F}_{\mathrm{ssw}}(0)=1$ for all boxes, as the borehole is assumed to be filled with surface seawater during logging and clean-out operations (Mottl and Gieskes, 1990). We also specify that the fraction of surface water in box $\mathrm{n}=0$ (bottom water) set at a depth of $370 \mathrm{mbsf}$ is $\mathrm{F}_{\mathrm{ssw}, 0}=0$, and hence $\mathbf{b}=0$ (Eq. 6). For a first analysis, we assume that $\beta$ is constant for all boxes. Figures $3 \mathrm{~A}-\mathrm{C}$ show the simulated profiles for several values of $\beta$ in comparison to the fraction of surface seawater as calculated using the tritium analyses for Legs 83,92 , and 111. The shape of the profile produced is convex upward in all cases. Comparison to the tritium data in the deepest samples from each leg suggests that modeled exchange coefficients of $2.5 \times 10^{-6} \mathrm{~s}^{-1}$ and $6.6 \times 10^{-6} \mathrm{~s}^{-1}$ fit the data for Legs 83 and 111 , respectively. For Leg 92 , a much greater exchange coefficient of $2 \times$ $10^{-5} \mathrm{~s}^{-1}$ is required to obtain the observed $\mathrm{F}_{\mathrm{ssw}}$.

Table 2. Model parameters for simulation of borehole mixing for the various suites of borehole fluid samples.

\begin{tabular}{rrrc}
\hline Leg & $\begin{array}{r}\text { Depth } \\
\text { (mbsf) }\end{array}$ & $\begin{array}{c}\text { Interim time } \\
\text { (days) }\end{array}$ & $\begin{array}{c}\text { Number of } \\
\text { boxes }(N)\end{array}$ \\
\hline 83 & 836 & 711 & 15 \\
92 & 1350 & 470 & 32 \\
111 & 1350 & 1233 & 32 \\
137 & 1562 & 1633 & 40 \\
\hline
\end{tabular}

Notes: The total depth simulated is the maximum depth penetrated on the previous drilling leg. Time is the interim between the cessation of drilling on the previous leg and the collection of borehole fluid samples. The number of boxes in the simulation is simply the number of 30-m boxes below a depth of $370 \mathrm{mbsf}$, which corresponds to the upper boundary of the model.
Given the stability of the thermal gradient in the deeper section of the hole (below $400 \mathrm{mbsf}$ ), we would expect reasonable agreement for the value of $\beta$ between legs. To evaluate the apparent discrepancies modeled, we first consider the calculation of the fraction of surface seawater remaining $\left(\mathrm{F}_{\mathrm{ssw}}\right)$ from the measured tritium concentrations. This calculation depends on two critical assumptions. First, the concentration of tritium in surface seawater must be known. The tritium concentration in the surface-water originally placed in the borehole was only measured for the fluids appropriate for Leg 83; the other surface-water concentrations were calculated assuming radioactive decay from the Leg 83 value. The surface-water tritium concentrations calculated in this way should be greater than actual surface-water tritium concentration, as in addition to radioactive decay, vertical and horizontal transport processes of the ocean will decrease the surface-water tritium concentrations. Thus, the values of $\mathrm{F}_{\mathrm{ssw}}$ calculated would be systematically low for Legs 92 and 111. Error in this direction would result in a decrease in the $\beta$ required for agreement between simulated and measured $F_{\mathrm{ssw}}$. Second, the borehole must have been entirely filled with undiluted surface seawater upon leaving the site. This is probably a safe assumption except for the case of Leg 92, in which the collected fluids contained large quantities of drilling mud that had not been effectively flushed from the borehole (Gieskes et al., 1986). Because the initial condition for the borehole fluids during Leg 92 must have been $\mathrm{F}_{\mathrm{ssw}}<1$, it is not surprising that the simulated mixing for Leg 92 required a much larger value of $\beta$ than for the other legs. Borehole conditions encountered during Leg 92 precluded efficient flushing of the hole; thus, the initial condition cannot be defined and modeling the $\mathrm{F}_{\mathrm{ssw}}$ for Leg 92 is futile.

The assumption that $\beta_{i}$ is constant throughout the borehole and during the time between drilling legs must also be questioned. Because temperature profiles in the interim between drilling legs are essentially identical, we can probably safely assume that thermal conditions in the hole have not varied substantially. Therefore, $\kappa_{i}$ (and thus $\beta_{i}$ at constant $h$ ) should be constant between legs. The assumption that $\beta_{i}$ is constant with depth in the borehole is another matter. By assuming that $\beta_{i}$ is constant for all boxes, we are inherently assuming that all boxes have the same volume (Eq. 3b). Because our model has boxes of constant height, variations in the volume can only occur by variation in the borehole radius $(r)$. The value of $\beta_{i}$ will be inversely proportional to the radius squared, using Equation 3 (and $V_{i}$ $\left.=\pi r_{i}^{2} h\right)$ :

$$
\beta_{i}=\beta_{j} \frac{r_{j}^{2}}{r_{i}^{2}},
$$

Caliper logs taken during Leg 148 (Shipboard Scientific Party, 1993 ) indicate that the borehole radius above $850 \mathrm{mbsf}$ is substantially larger than below this depth, with average values on the order of $18 \mathrm{~cm}$ and $14 \mathrm{~cm}$, respectively. Using Equation 8, we predict an increase in $\beta_{i}$ in the deeper section with $\beta_{\text {below }} 850$ mbsf $\cong 1.65 \beta_{\text {above } 850 \mathrm{mbs}}$. Figure $3 \mathrm{D}$ shows the results for Leg 111 using this relationship for $\beta_{\text {; }}$ between the shallow and deep sections of the borehole. The data fit the simulation for $\beta_{i}$ equal to $5 \times 10^{-6} \mathrm{~s}^{-1}$ and $8.25 \times 10^{-6} \mathrm{~s}^{-1}$ for the shallow and deep section, respectively. Note that this alteration of the model forces the value in the shallow section closer to that estimated for Leg 83 (in which there is no deep section). The point from 760 mbsf (Fig. 3D, Leg 111) still falls below the simulated profile, but given the errors associated with calculation of $F_{\text {ssw }}$ from the tritium concentrations, we believe this approach is appropriate. Overall, we estimate $\beta_{i}$ for the upper 850 mbsf to be between 2.5 to $5 \times 10^{-6} \mathrm{~s}^{-1}$, with an increase in $B_{i}$ in the deeper section by a factor of 1.65 .

\section{Simulation of Elemental Profiles: Magnesium Removal}

Equation 6 can also be used to simulate the downhole elemental concentration profiles. We have previously argued that the reacted fluid component of the borehole fluids originates in the rubble at the 

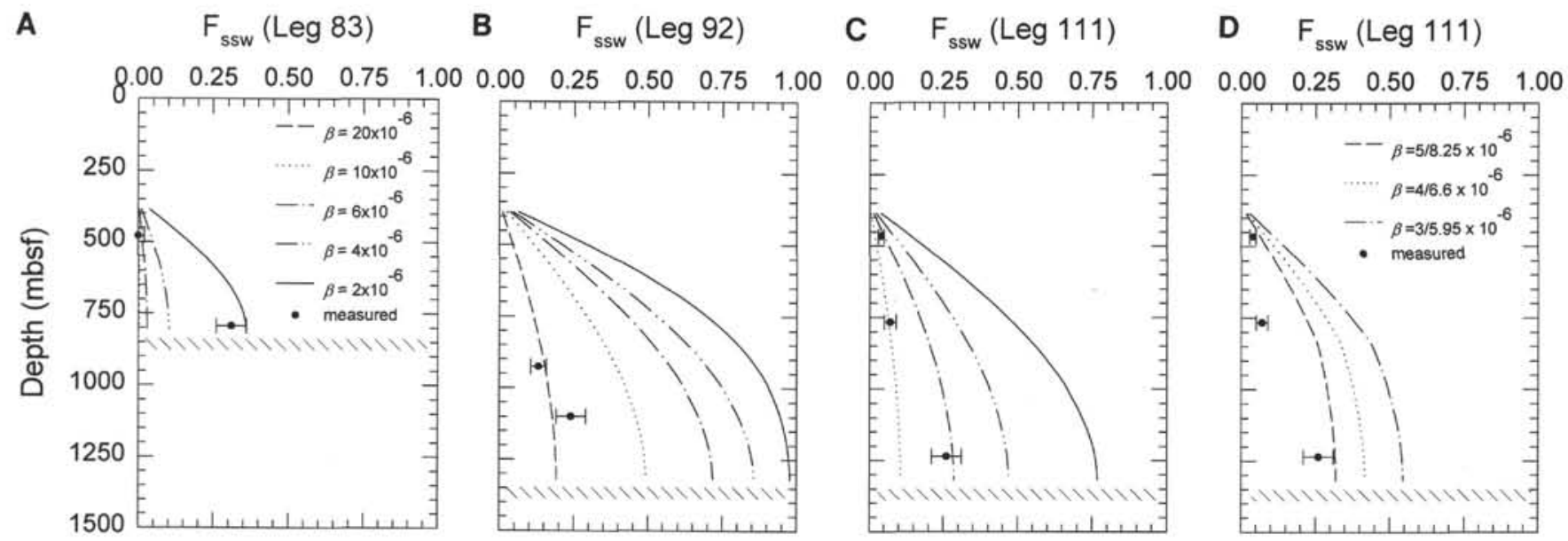

Figure 3. Simulation of fraction surface seawater $\left(\mathrm{F}_{\mathrm{ssw}}\right)$ remaining for Legs 83 (A), 92 (B) and 111 (C), assuming $\beta$ is constant through the entire borehole. D. Simulation for Leg 111, assuming $\beta_{\text {below } 850 \text { mbsf }}=1.65 \beta_{\text {abrve } 850 \text { mbsf }}$ as expected from the change in borehole diameter (see text, Eq. 8). Values for $\mathrm{F}_{\mathrm{ssw}}$ calculated from tritium analyses (Table 1) are shown for comparison. Hatched area represents the depth of the hole bottom. Hatched area shows the borehole depth for each leg.

hole bottom (Magenheim et al., 1992, 1995). For Mg we can assume that the concentration of $\mathrm{Mg}$ in the reaction zone is equal to zero (see Magenheim et al., 1995, for justification). If we assume that the flux from box $\mathrm{n}$, into the reaction zone is dependent on the concentration in box $\mathrm{n}$ (as in Eq. 1), then the time rate of change for the concentration of $\mathrm{Mg}$ in box $\mathrm{n}$ because of this process is

$$
\left(\frac{d C_{n}}{d t}\right)_{n, r}=-\alpha_{n, r} C_{n},
$$

where $\alpha_{n, r}$ is the exchange coefficient $\left(\mathrm{s}^{-1}\right)$ appropriate for exchange between box $\mathrm{n}$ and the fluid in the rubble. Then from Equation $4 \mathrm{~b}$ the net change in concentration over a time interval $d t$ for box $\mathrm{n}$ is

$$
\frac{d C_{n}}{d t}=\beta_{n} C_{n-1}-\left(\beta_{n}+\alpha_{r}\right) C_{n} .
$$

The $\mathrm{Mg}$ concentration for surface seawater $(51.7 \mathrm{mM})$ is equal to our initial condition $\mathrm{Mg}(0)$ and the deep water value of $53.5 \mathrm{mM} \mathrm{Mg}$ is used for the calculation of $\mathbf{b}(\mathrm{Eq} .5 \mathrm{~b})$. The value of matrix $\mathbf{A}$ is computed using the range of $\beta_{i}$ previously estimated from the tritium analyses, at variable $\alpha_{r}$.

The simulated $\mathrm{Mg}$ profiles are compared with the measured $\mathrm{Mg}$ concentrations in Figure 4. Using the range of values of $\beta_{i}$ suggested by the previous simulation, excellent agreement is obtained for values of the $\alpha_{r}$ of $6 \times 10^{-8}$ to $8 \times 10^{-8} \mathrm{~s}^{-1}$ for Legs 83,111 , and 137. The data from Leg 92 are best fit for $\alpha_{r}$ of $8 \times 10^{-8}$ to $12 \times 10^{-8} \mathrm{~s}^{-1}$. The greater values of $\alpha_{r}$ for the Leg 92 simulation are possibly the result of additional loss of $\mathrm{Mg}$ caused by reaction of the borehole fluids with drilling mud left in the borehole (Gieskes et al., 1986). The excellent agreement among the simulations for the other legs suggests that this description of vertical mixing within the borehole coupled with exchange with a reacted fluid component present in the rubble is valid. The agreement between the modeled and measured $\mathrm{Mg}$ profiles appears better than that for the simulation of $\mathrm{F}_{\mathrm{ssw}}$. This is probably related to the errors involved in calculating $F_{\text {ssw }}$ from the measured tritium concentrations, and the fact that the initial condition for the simulation of $\mathrm{Mg}$ concentrations $\left(\mathrm{Mg}_{i}[0]\right)$ is less sensitive to completely filling the borehole with surface seawater as the $\mathrm{Mg}$ concentrations of surface and deep seawater are similar.

The magnitude of the values for $\beta$ and $\alpha$ can be used to make inferences regarding the mechanism for exchange with this reacted fluid component. Because $\beta$ (or $\alpha$ ) is simply the diffusivity divided by the diffusive path length squared, we can compare the estimated values of the exchange coefficient to those for molecular processes. For $\mathrm{Mg}$ at $25^{\circ} \mathrm{C}$ molecular diffusivity in water, $\kappa_{\text {molecular }}=0.71$ $\times 10^{-10} \mathrm{~m}^{2} / \mathrm{s}$. Assuming a maximum borehole temperature of $150^{\circ} \mathrm{C}$, using the relationship in McDuff and Gieskes (1976), we can compute an increase in the molecular diffusivity of $\mathrm{Mg}$ to $\kappa_{m o}$. lecular $=3.8 \times 10^{-10} \mathrm{~m}^{2} / \mathrm{s}$. For the exchange coefficient describing mixing within the borehole $\left(\beta_{i} \cong 5 \times 10^{-6} \mathrm{~s}^{-1}\right)$ and a path length $(h)$ of $30 \mathrm{~m}$, we can calculate $\kappa_{\text {mix }}=4.5 \times 10^{-3} \mathrm{~m}^{2} / \mathrm{s}$ (Eq. 5), which is 7 orders of magnitude greater than molecular diffusivity. Thus, ignoring molecular diffusion while modeling the mixing of surface water out of the borehole is justified. For the case of exchange between box $\mathrm{n}$ and the reacted fluid reservoir, we can compute a path length assuming that this exchange is driven by molecular diffusion. If we assume a porosity of $90 \%$ in the rubble pile, we can compute a bulk diffusivity of $3.1 \times 10^{-10} \mathrm{~m}^{2} / \mathrm{s}$. Using a value of $\alpha_{r}$ $=8 \times 10^{-8} \mathrm{~s}^{-1}$, the calculated value of the molecular diffusive path length is $6.2 \mathrm{~cm}$. This appears to be a reasonable distance for molecular diffusion to operate over, and hence exchange between the fluid in box $\mathrm{n}$ and in the rubble zone is apparently by molecular diffusion.

\section{Effects of Mixing on Borehole Temperatures}

Borehole fluid temperatures have been measured before drilling during each expedition to Hole 504B. Below $500 \mathrm{mbsf}$, the predrilling temperature profile on different occasions has been relatively unchanged in both absolute temperature and temperature gradient (see Shipboard Scientific Party, 1992), and is considered to be in equilibrium with formation temperatures and dynamic processes occurring in the borehole. A curious decrease in the temperature gradient $(d T / d z)$ of $40 \%$ was observed below 850 mbsf by Gable et al. (1989). This decrease in $d T / d z$ could not be explained by changes in thermal conductivity of the formation and may reflect a true decrease in heat flow in the deeper section of the crust (Gable et al., 1989). Fisher and Becker (1991) calculated that the downhole velocity required to reduce the thermal gradient by $40 \%$ over the deepest $500 \mathrm{~m}$ (Leg 111, 830-1330 mbsf) was on the order of $0.02 \mathrm{~m} / \mathrm{s}$. However, estimates of fluid flow into the deepest $1000 \mathrm{~m}$ based on the measured permeability predicted underpressure yielded a maximum velocity of $1.3 \times 10^{-4} \mathrm{~m} / \mathrm{s}$, which is much less than the flow required to produce the observed reduction in $d T / d z$ (Fisher and Becker, 1991). Calculations of the stability of the borehole fluids based on the Rayleigh number (Fisher and Becker, 1991) indicated that the borehole 
A

$$
\begin{aligned}
& \operatorname{Leg} 83 \\
& \mathrm{Mg}(\mathrm{mM})
\end{aligned}
$$

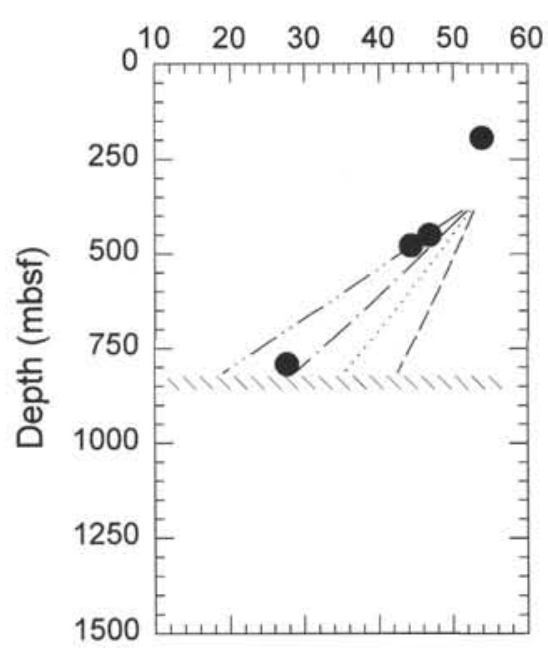

B $\operatorname{Leg} 92$
$\mathrm{Mg}(\mathrm{mM})$
C

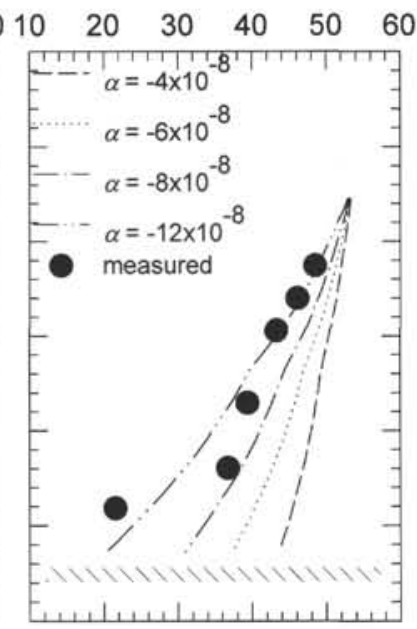
$\operatorname{Leg} 111$
$\mathrm{Mg}(\mathrm{mM})$
D

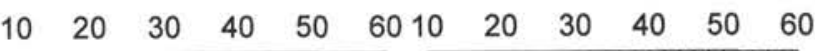
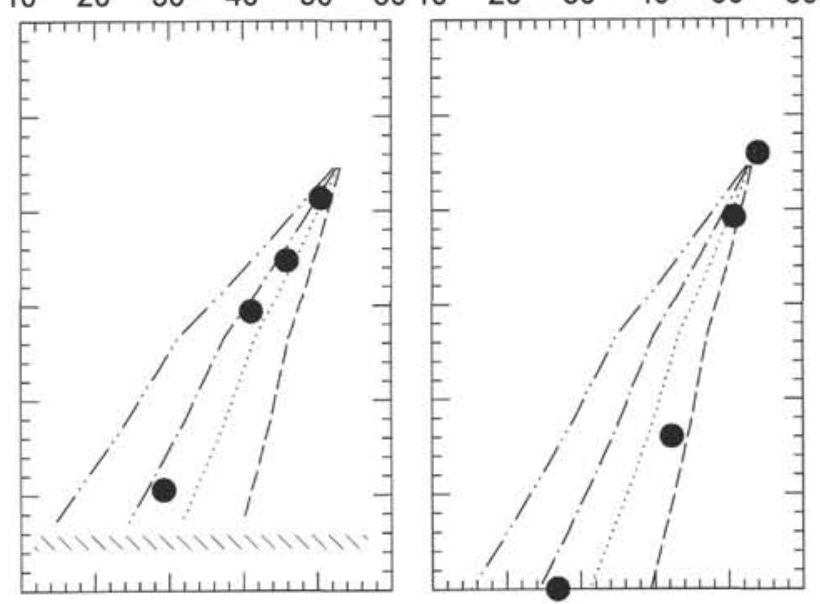

Figure 4. Simulation of Mg concentration profiles in Hole 504B for Legs 83 (A), 92 (B), 111 (C), and 137, (D). The profiles were simulated using variable val-

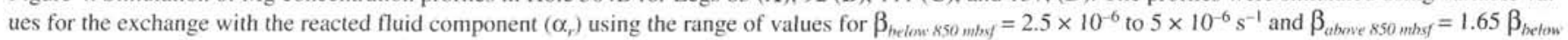
$850 \mathrm{mbs}$ as estimated from the $\mathrm{F}_{\mathrm{ssw}}$ simulation (Fig. 3D, see text). Hatched area represents the depth of the hole bottom.

fluids should be supercritical for free convection, but the quantitative description of the convective heat flux was not determined because of the unknown geometry of the borehole. Herein, we apply the results of the above mixing simulation to the borehole temperatures to answer two questions: (1) are the linear temperature gradients disturbed using the calculated values of $\beta$ based on the geochemical evidence (Case 1)? and (2) if borehole mixing/convection is responsible for the reduction in heat flow below $850 \mathrm{mbsf}$, are the calculated exchange coefficients $\left(\beta_{i}\right)$ necessary for such a reduction in heat flow compatible with geochemical observations (Case 2)?

First, we define the heat content of box $\mathrm{i}$ as $Q_{i}$ (in joules):

$$
Q_{i}=C_{i, i} V_{i} T_{i},
$$

where $C_{i, i}$ is the volumetric heat capacity of box $i\left(\mathrm{~J} \mathrm{~m}^{-3} \mathrm{~K}^{-1}\right)$ and $T_{i}$ is the temperature of box $i(\mathrm{~K})$. There are three components to the flux of heat for each box: radial heat flux $\left(d Q_{r} / d t\right)$, vertical heat flux resulting from thermal conduction $\left(d Q_{t} / d t\right)$, and heat flux caused by borehole mixing $\left(d Q_{\operatorname{mix}} / d t\right)$. The heat flux through the walls of a box can be calculated in a manner similar to Becker et al. (1983) after Jaeger (1961):

$$
\frac{d Q_{r, i}}{d t}=\frac{8 h}{\pi} K_{e, i} I(\tau) \Delta T_{(r, \infty), i},
$$

where $K_{e, i}$ is the thermal conductivity $(\mathrm{W} /[\mathrm{m} \cdot \mathrm{K}])$ of the formation adjacent to box $\mathrm{i}, I(\tau)$ is a complicated integral evaluated over the dimensionless time ( $\tau=\kappa t / r^{2}$, where $\kappa$ is the thermal diffusivity), and $\Delta T_{(r, \infty), i}$ is the temperature difference between the undisturbed temperature at infinite distance from the borehole and the borehole temperature for box $\mathrm{i}\left(\Delta T_{i, \infty \infty), i}=T_{\infty}-T_{i}\right)$. The conductive vertical heat flux is:

$$
\frac{d Q_{c, i}}{d t}=-\pi r^{2} K_{c} \frac{d T}{d z}
$$

where $K_{c}$ is the thermal conductivity of water (assumed constant for this model). The flux of heat resulting from borehole mixing can be described by Equation 4:

$$
\frac{d Q_{\operatorname{mix}}}{d t}=\beta_{i} V_{i} C_{v, i-1} T_{i-1}-2 \beta_{i} V_{i} C_{v, i} T_{i}+\beta_{i} V_{i} C_{v, i+1} T_{i+1},
$$

or

$$
\frac{d Q_{m i x}}{d t}=-\pi r^{2} \beta_{m i x} h^{2} C_{v} \frac{d T}{d z} .
$$

Assuming that the net heat flux is the sum of Equations 10 through 12 , and setting it equal to zero (there is no net gain or loss of heat from the box):

$$
\frac{d Q_{n e t, i}}{d t}=0=\frac{d Q_{r, i}}{d t}+\frac{d Q_{c, i}}{d t}+\frac{d Q_{m i x, i}}{d t},
$$

or

$$
\left(K_{c}+\beta_{m i x} h^{2} C_{v}\right) \frac{d T}{d z}=\frac{8 h K_{e} I(\tau)}{\pi^{2} r^{2}} \Delta T_{(r, \infty), f} .
$$

Values for the various parameters used are given in Table 3. The solution to Equation 13 above can only be applied for a specified time $t$, as $I(\tau)$ is evaluated over for a specific time interval. The values of $I(\tau)$ in Table 3 are for the appropriate conductivity and interim time for Leg 111. The values for $T_{\infty, i}$ can be calculated for each depth assuming the measured borehole temperatures and thermal gradients with no mixing $(\beta=0)$. It is then possible to simulate the temperature profile using the values for $\beta_{i}$ as estimated above (Case 1, Fig. 5A). Note that in this case, the calculated and measured temperature profiles are essentially identical. Therefore, borehole mixing to the extent necessary to remove the observed quantity of surface seawater has had minimal effect on the thermal structure of the borehole.

For Case 2, we assume that the reduction in heat flow, evident from the temperature profile, is caused by enhanced borehole mixing below $850 \mathrm{mbsf}$ to calculate the magnitude of $\beta_{i}$ for each depth interval from Equation 13. The value for $T_{\infty, i}$ can be estimated by assuming constant heat flow with depth in the formation (Case 2, Fig. 5B). A slight increase in thermal conductivity (Table 3 ) yields a reduced temperature gradient of $0.094^{\circ} \mathrm{C} / \mathrm{m}$ in the deeper section of the for- 
Table 3. List of symbols and values for parameters necessary for the simulation of the effect of mixing on the borehole temperatures (Eq. 13).

\begin{tabular}{|c|c|c|c|}
\hline Symbol & Parameter & Value & Reference \\
\hline$K_{r}$ & Formation thermal conductivity & $\begin{array}{l}1.67 \mathrm{~W} /(\mathrm{m} \cdot \mathrm{K})(370-850 \mathrm{mbsf}) \\
2.05 \mathrm{~W} /(\mathrm{m} \cdot \mathrm{K})(850-1300 \mathrm{mbsf})\end{array}$ & Gable et al. (1989) \\
\hline$C_{v}$ & Volumetric heat capacity of water & $\mathrm{J} \mathrm{m}^{-3} \mathrm{~K}^{-1}$ (dependent on $T, P$ ) & Haar et al. (1984) \\
\hline$r$ & Hole radius & $\begin{array}{l}0.18 \mathrm{~m}(370-850 \mathrm{mbsf}) \\
0.14 \mathrm{~m}(850-1330 \mathrm{mbsf})\end{array}$ & Shipboard Scientific Party (1993) \\
\hline$h$ & Height of a box & $30 \mathrm{~m}$ & \\
\hline$T$ & Temperature in box $\mathrm{i}$ & ${ }^{\circ} \mathrm{C}$ (based on $T \log$ ) & Gable et al. (1989) \\
\hline$T_{-}$ & $T$ at infinite distance from box $\mathrm{i}$ & ${ }^{\circ} \mathrm{C}$ (see text) & \\
\hline$I(\tau)$ & Complex integral tabulated by Jaeger & $\begin{array}{l}0.660(370-850 \mathrm{mbsf}) \\
0.643(850-1330 \mathrm{mbsf})\end{array}$ & $\begin{array}{l}\text { A. Fisher (pers, comm.. 1992); } \\
\text { after Jeager (1961) }\end{array}$ \\
\hline
\end{tabular}

A

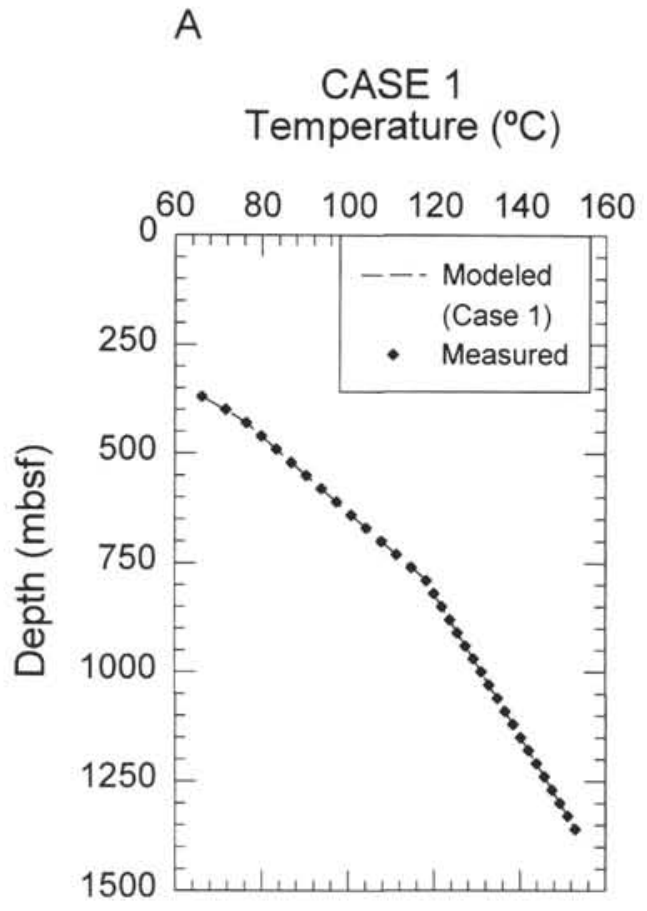

B

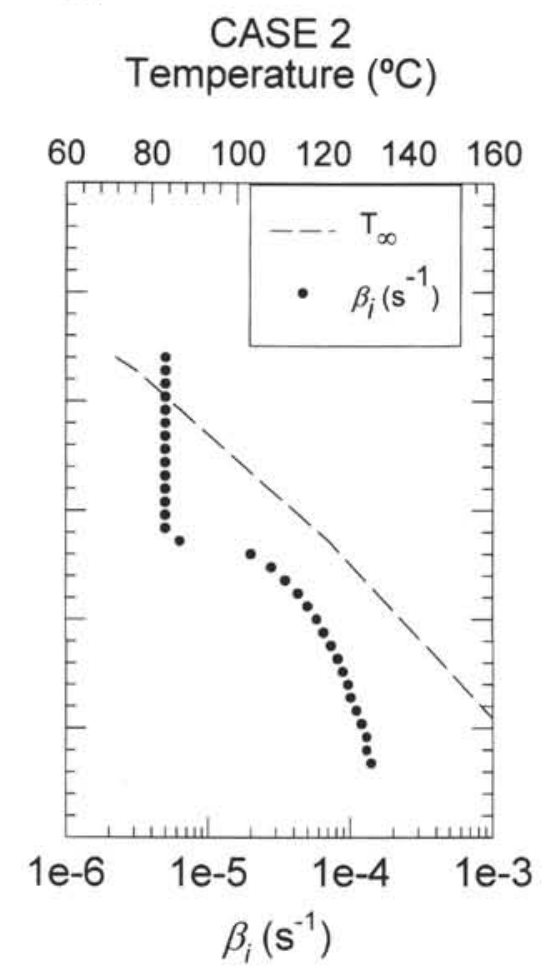

C

CASE 2 $\mathrm{F}_{\mathrm{ssw}}$ $\begin{array}{llll}0.0 & 0.1 & 0.2 & 0.3\end{array}$

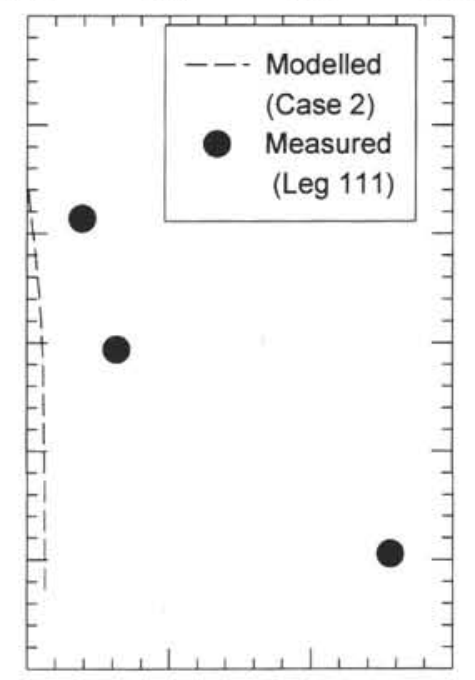

Figure 5. Effects of mixing on the borehole fluid temperatures. A. Comparison of the calculated temperature profiles based on the values of $\beta_{i}$ estimated from the geochemical parameters (Case 1) to the measured borehole temperatures from Leg 111 (Gable et al., 1989). B. $T_{\tau}$ (Case 2) is the expected temperature at infinite distance from the borehole if the heat flow measured in the upper $850 \mathrm{mbsf}$ is extrapolated to the total depth and the values of $\beta_{i}$ required if mixing is responsible for the $40 \%$ reduction in $d T / d z$ observed below $850 \mathrm{mbsf}$ (Case 2). Note: the values of $\beta_{i}$ above 850 mbsf are assumed to be $5 \times 10^{-6} \mathrm{~s}^{-1}$ from the previous analyses. C. Comparison of the $\mathrm{F}_{\mathrm{sww}}$ remaining in the hole after 1233 days between Legs 92 and 111 , calculated using the $\beta_{i}$ necessary to reduce the borehole temperatures below 850 mbsf (Case 2. Fig. 5B) to the measured values of $\mathrm{F}_{\mathrm{ssw}}$ based on the tritium analyses (Table 1).

mation. The value of $\Delta T$ is simply the difference between the temperature assuming constant heat flow and the measured borehole temperature. If the reduction on $d T / d z$ in the borehole is related to borehole convection, this process is responsible for lowering the temperature by as much as $10^{\circ} \mathrm{C}$ in the lower part of the hole. The computed values of $\beta_{i}$ are presented vs. depth in Figure 5B. The calculated exchange efficiency $\left(\beta_{i}\right)$ increases monotonically with depth below 850 mbsf to values almost 2 orders of magnitude greater than inferred by the geochemical gradients. Figure $5 \mathrm{C}$ presents the result for the fraction of surface seawater remaining $\left(\mathrm{F}_{\mathrm{ssw}}\right)$ calculated using the values of $\beta_{i}$ necessary for the reduction in $d T / d z$ below 850 mbsf. Note that the magnitude of convective exchange required for reduction of the borehole temperature gradient results in almost complete removal of surface water from the borehole. Given the fact that a significant portion of surface seawater remained in the hole during the interim between Legs 92 and 111, we conclude that convective mixing could not be responsible for the apparent reduction in heat flow with depth.

\section{CONCLUSIONS}

We have used a time-dependent box model to simulate the observed geochemical profiles found in borehole fluids from Hole 504B for several drilling legs. Previously, tritium concentrations were used to suggest that the surface seawater, originally placed in the borehole at the end of the leg before sampling, was replaced with formation fluids by molecular diffusion and with bottom seawater through downhole mixing (Mottl and Gieskes, 1990). Evidence presented in this paper, including reevaluation of the data presented in Mottl and Gieskes (1990, Table 1), suggests that the tritium concentrations can be explained by downhole mixing alone. Although, in theory, tritium 
concentration is an excellent surrogate for the initial fluid placed in the borehole, some serious problems exist with this interpretation. Foremost, we assume that the borehole is filled completely with surface seawater during circulation at the end of a drilling leg. Because insufficient flushing of the hole led to poor borehole fluid samples during Legs 92 and 148 (Gieskes et al., 1986; Shipboard Scientific Party, 1993), we must question whether the borehole fluids were completely replaced with surface water on other legs. As the concentration of tritium in surface waters has decreased by radioactive decay and vertical exchange, in the future it is imperative that borehole fluid samples be taken before leaving the borehole to establish the initial condition. Of course, because analysis of tritium is expensive and requires large samples, an alternate tracer would be desirable. An attempt to spike the borehole fluids with sodium bromide (increasing $\mathrm{Br}$ concentration by a factor of 4) was made for the first time at the end of Leg 148 (Shipboard Scientific Party, 1993). Although every effort was made to fill the entire borehole with this spiked fluid, analysis of a sample taken from 475 mbsf indicated that most of this spiked seawater resided in the bottommost $1500 \mathrm{~m}$ of the borehole. Assessment of the $\mathrm{Br}$ spiking experiment awaits future borehole sampling of Hole 504B on the next drilling leg to visit this site.

Magenheim et al. (1995) have discussed the nature of the reacted fluid component; they suggest that the reaction zone was within the rubble that accumulates at the hole bottom during the interim between drilling legs. Mathematical simulation of $\mathrm{Mg}$ concentrations supports the explanation that the geochemical trends are caused by a combination of displacement of the borehole fluids by downhole mixing of bottom seawater and an input of reacted fluid into the bottom of the hole. The exchange between the fluids in the reaction zone and the borehole appear to be of a magnitude consistent with molecular diffusion. Thus, there is no evidence that formation fluid is present within the borehole as previously hypothesized.

In addition to analyzing the downhole chemical profiles, we have considered what effects the mixing necessary to produce the geochemical profiles would have on the borehole temperatures. With the calculated mixing coefficient $\left(\beta_{\text {mix }} \cong 5 \times 10^{-6} \mathrm{~s}^{-1}\right)$, we find no detectable effect on the downhole temperatures. Several authors have suggested that convective mixing may explain the $40 \%$ reduction in thermal gradient observed in Hole 504B (Gable et al., 1989; Fisher and Becker, 1991). We calculated that the mixing coefficient would have to increase monotonically below $850 \mathrm{mbsf}$ to greater than two orders of magnitude higher than those required by the geochemical trends. Mixing to this extent would have removed all remnants of surface seawater from the borehole. Reduction of the heat flow below $850 \mathrm{mbsf}$ by enhanced borehole mixing is considered unlikely in light of the presence of tritium in the borehole fluid samples.

\section{ACKNOWLEDGMENTS}

We thank Dr. Andrew Fisher for his helpful comments and suggestions regarding treatment of the effects of mixing on the temperature profile in Hole 504B. Dr. Michael Mottl provided an insightful review that improved this manuscript. This research was funded by a grant from JOI/USSAC to AJM and NSF OCE-93-01730 to JG.

\section{REFERENCES}

Becker, K., Langseth, M.G., and Von Herzen, R.P., 1983. Deep crustal geothermal measurements, Hole 504B, Deep Sea Drilling Project Legs 69 and 70. In Cann, J.R., Langseth, M.G., Honnorez, J., Von Herzen, R.P., White, S.M., et al., Init. Repts. DSDP, 69: Washington (U.S. Govt. Printing Office), 223-236.

Becker, K., Langseth, M.G., Von Herzen, R.P., Francis, T.J.G., Anderson, R.N., Honnorez, J., Adamson, A.C., Alt, J.C., Emmermann, R., Kempton, P.D., Kinoshita, H., Laverne, C., Mottl, M.J., and Newmark, R.L., 1982. In situ electrical resistivity and bulk porosity of the oceanic crust, Costa Rica Rift. Nature, 300:594-598.

Fisher, A.T., and Becker, K., 1991. The reduction of measured heat flow with depth in Hole 504B: evidence for convection of borehole fluids? Sci. Drill., 2:34-40.

Gable, R., Morin, R.H., and Becker, K., 1989. Geothermal state of Hole 504B: ODP Leg 111 overview. In Becker, K., Sakai, H., et al., Proc. ODP, Sci. Results, 111: College Station, TX (Ocean Drilling Program), $87-96$.

Gieskes, J.M., Kastner, M., Erzinger, J., Boulègue, J., and Hart, S.R., 1986. Geochemical studies in Hole 504B, Leg 92. In Leinen, M., Rea, D.K., et al., Init. Repts. DSDP, 92: Washington (U.S. Govt. Printing Office), 547562 .

Haar, L., Gallagher, J.S., and Kell, G.S., 1984. NBS/NRC Steam Tables, Thermodynamic and Transport Properties and Computer Programs for Vapor And Liquid States in SI Units: Washington (Hemisphere Publ.), 263-266.

Jaeger, J.C., 1961. The effect of drilling fluid on temperatures measured in boreholes. J. Geophys. Res., 66:563-569.

Lasaga, A.C., 1980. The kinetic treatment of geochemical cycles. Geochim. Cosmochim. Acta, 44:815-828.

Magenheim, A.J., Bayhurst, G., Alt, J.C., and Gieskes, J.M., 1992. ODP Leg 137, borehole fluid chemistry in Hole 504B. Geophys. Res. Lett., 19:521524.

Magenheim, A.J., Spivack, A.J., Alt, J.C., Bayhurst, G., Chan, L.-H., Zuleger, E., and Gieskes, J.M., 1995. Borehole fluid chemistry in Hole 504B, Leg 137: formation water or in-situ reaction? In Erzinger, J., Becker, K., Dick, H.J.B., and Stokking, L.B. (Eds.), Proc. ODP, Sci. Results, 137/140: College Station, TX (Ocean Drilling Program), 141154.

McDuff, R.E., and Gieskes, J.M., 1976. Calcium and magnesium profiles in DSDP interstitial waters: diffusion or reaction? Earth Planet. Sci. Lett., 33:1-10.

Mottl, M.J., Druffel, E.R.M., Hart, S.R., Lawrence, J.R., and Saltzman, E.S., 1985. Chemistry of hot waters sampled from basaltic basement in Hole 504B, Deep Sea Drilling Project Leg 83, Costa Rica Rift. In Anderson, R.N., Honnorez, J., Becker, K., et al., Init. Repts. DSDP, 83: Washington (U.S. Govt. Printing Office), 315-328.

Mottl, M.J., and Gieskes, J.M., 1990. Chemistry of waters sampled from oceanic basement boreholes, 1979-1988. J. Geophys. Res., 95:9327-9342.

Pezard, P.A., 1990. Electrical properties of mid-ocean ridge basalt and implications for the structure of the upper oceanic crust in Hole 504B. J. Geophys. Res., 95:9237-9264.

Shipboard Scientific Party, 1992. Site 504. In Becker, K., Foss, G., et al., Proc. ODP, Init. Repts., 137: College Station, TX (Ocean Drilling Program), $15-55$.

1993. Site 504. In Alt, J.C., Kinoshita, H., Stokking, L.B., et al., Proc. ODP, Init. Repts., 148: College Station, TX (Ocean Drilling Program), 27-121.

Date of initial receipt: 12 August 1994

Date of acceptance: 26 January 1995

Ms 148SR-116 